\title{
Motivations, Expectations and Experiences of Expatriate Academic Staff on an International Branch Campus in China
}

\author{
Li (Lily) CAl, University of Nottingham Ningbo China \\ Christine Hall, University of Nottingham UK
}

\begin{abstract}
This article explores the experiences of non-Chinese academic staff working on an international branch campus in China. The paper presents findings from an interview study which explored the expectations of expatriate staff and what motivated them to want to work abroad. The second part of the paper reports on whether and how these expectations and motivations were fulfilled. The findings suggest that, although staff found many benefits from working on the international branch campus, they were insufficiently prepared for the structural and cultural differences inherent in working as an academic in China. The authors argue that more of the academics' initial expectations and motivations could have been realised if better staff induction and ongoing collective professional development had been in place. In particular university level discourse, communicated through policy and marketing texts, which promoted the vision of one inclusive and diverse international university community, militated against attention being paid to the structural, political and cultural differences inherent in working as an academic in China. The authors argue that professional development that acknowledges the differences, difficulties and disjunctions that staff are likely to encounter in their work is important in building successful international branch campuses both at the level of the organisation and of the individual.
\end{abstract}

Key words internationalisation of higher education (IHE), international branch campus (IBC), international academic staff (IAS), staff development

Since the turn of the century there has been a rapid growth in the number of universities across the world establishing international branch campuses (Dessoff, 2011). Between 2002 and 2015, the total number of international branch campuses [IBCs] increased from about 20 to 229; a further 22 campuses were at the planning stage and 27 had already closed (CrossBorder Education Research Team, 2015; University World News, 2015). The Cross-Border Education Research Team defines an IBC as "an entity that is owned, at least in part, by a foreign education provider; operated in the name of the foreign education provider; engages in at least some face-to-face teaching; and provides access to an entire academic program that leads to a credential awarded by the foreign education provider" (Cross-Border Education Research Team, 2015). It is this definition of international branch campuses that is used in this article. 
The rapid rise in the number of $\mathrm{IBCs}$ has involved increasing numbers of academic staff in moving to create/recreate versions of national universities in new contexts. This work involves new (and changing) challenges, to the institutions and to the staff themselves. Whilst the importance of these institutional challenges has been recognised and discussed in the literature (for example, Fielden, 2010; Olcott, 2009; Shams \& Huisman, 2012 and 2014; Sadler, 2015), there is, as yet, relatively little fine-grained exploration of the experiences and motivations of the staff involved. As both Shaw (2013) and Bodycott \& Walker (2000) point out, the focus has been predominantly on the experiences of students, rather than the experiences of their teachers (although see Austin et al, 2014; Chapman et al, 2014; Ferguson, 2011; Froese, 2011 and Garson, 2005 for studies of expatriate staff in various locations around the world). The starting point for the research that underpins this article was, therefore, to explore in depth, through qualitative research, the motivations, expectations and experiences of expatriate staff on an IBC in order to contribute to understandings about the human costs and benefits of the processes of internationalising higher education.

The study reported here focuses on the Chinese context. The rapid growth of China's economy, combined with a shortage of domestic supply, has resulted in a tremendous demand for internationalised higher education (Altbach, 2009; Chiang, 2012; Helms, 2008; Morgan \& Wu, 2011; World Bank, 2011). The Outline of China's National Plan for Medium and Longterm Education Reform and Development 2010-2020 urges Chinese higher education institutions to "open their best faculties to the world, and to participate in or set up collaborative international academic organisations" (China, 2010, p 21). This exhortation has been very well received by the exporters of higher education, including the USA, UK and Australia, who have appreciated the opportunities offered to expand beyond their national boundaries. High profile politicians have encouraged and supported their national higher education sectors to internationalise, and China has been seen as a particularly desirable destination. Former prime ministers Tony Blair and John Howard, for example, have used similar rhetoric about the 'global war' for talent that underpins the competition for international higher education students and establishing offshore programmes (AP, 2011). Trade missions to China routinely include senior university staff keen to extend their universities' business interests and promote the officially endorsed desire for academic collaborations.

As a consequence of these initiatives and the benign political context, the number of IBCs, or Sino-Foreign Joint Ventures (中外合作办学机构) in China, grew from 20 in 2013 to 28 in 2015, making it the second largest importer of branch campuses after the United Arab Emirates, which had 32 (Cross-Border Education Research Team, 2015). The majority of these are niche institutions with relatively small enrolment. However, four are larger-scale IBCs (Duke Kunshan University, established 2014; New York Shanghai, established 2013; Xi'an JiaotongLiverpool University, established 2006; The University of Nottingham Ningbo China, established 2004) which seek to offer a range of disciplines at the undergraduate and postgraduate levels and to reflect the quality and experience of the institution's home 
campuses (Stanfield \& Qi, 2012). The research reported in this article took place at one of these larger-scale branch campuses, set-ups which seem highly likely to increase in number.

\section{Tensions in Staffing IBCs}

As IBCs have developed, in number and in size, the tensions inherent in managing them have begun to be explored in the literature. Shams and Huisman (2012) adopt a paradigm from business management literature to draw out the dichotomy between 'global integration' and 'local responsiveness'; that is, 'the question of prioritising the homogeneity of international markets or the heterogeneity of market preferences' (2012, p. 115). Following De Wit and Meyer (2004), Shams and Huisman argue that the split demands of IBCs' situation create a strategic paradox, in that the institution needs to accommodate contradictory requirements: on the one hand, the requirement to standardise and centralise in order to demonstrate consistent quality standards and to maintain the 'brand'; on the other hand, a requirement to adapt to the local regulations, partnerships and circumstances.

In terms of staffing, this tension plays out as a set of questions about proportions of secondments from the home campus to the IBC, the appointment of staff local to the IBC or the appointment of 'international' staff from elsewhere in the world. In the context of building a new branch higher education institution $(\mathrm{HEI})$, the staff mix is likely to be significant in the degree to which it becomes what Shams and Huisman call either a 'receptive' or an 'autonomous' subsidiary - i.e. highly integrated with the home campus or strongly adapted to the local context. This brings into play questions of power and authority (Fielden \& Gillard, 2011; Gannon, 2008) - as Dobos (2011) puts it, the problem of "serving two masters" - and how far the experience of the home campus can be recreated through the staffing and the curriculum of the IBC (Hughes, 2011; Smith, 2009).

Fielden and Gillard in their discussion of these tensions, conclude that universities will need to adopt human resources management policies like those of multinational companies (2011, p. 38). Salt and Wood (2014) extend this to consider how far UK universities are becoming like multinational commercial companies with regard to international staffing, and whether universities can learn lessons from the staffing policies and practices of multinationals. They conclude that the current system of staffing IBCs is unsustainable, but note also that there are significant differences between UK universities and multinational enterprises, not least the difference in infrastructure and notions of career progression.

Richardson and McKenna argued in 2000 that the experience of expatriate academics - as opposed to expatriate business executives - was under-researched. Their study of British academics in the UAE, Singapore and New Zealand, proposed four evocative metaphors ('explorer' and 'refugee' in relation to motivation to move overseas, and 'tightrope walker' and 'outsider' for the experience of expatriation), which they suggest can be used to facilitate better management practices and support cultural adjustment. Selmer and Lauring (2009) investigated issues of cultural adjustment for expatriate academics across 34 universities in five European countries. In contrast to earlier studies about business expatriates which had suggested, counter-intuitively, that cultural similarity and dissimilarity 
between the new and the home contexts were equally difficult to adjust to, Selmer et al concluded that there was no difference in expatriate academics' adjustment or the time it took them to become proficient in different contexts.

Some commentators identify the provision of effective support, which prepares staff to make the necessary adjustments, as a key issue that has not yet been effectively addressed in most universities (Dunn \& Wallace, 2006, 2008; Gribble \& Ziguras, 2003; Keevers et al, 2014; Ziguras, 2007). Hoare agrees, arguing that it is important that academics should be supported to develop intercultural competences, rather than being left alone, "swimming in the deep end" (Hoare, 2013). Tsang's (2001) study, which underlines the value of in-depth interviews in this area of research, suggests that pre-departure knowledge and social support are significant factors in affecting adjustment and have practical implications at the organisational level.

\section{Aims and Method}

This article seeks to contribute to understanding about the nature of these new staffing challenges by focusing on the lived experience of a group of academics who moved from the West to work in China. Mindful of Barrows' (2000) suggestion that there is often a gap between the rhetoric and the reality of internationalisation, this article focuses on two aspects of staff experience: original motivations and expectations to work on the international campus before moving; and actual experiences after the move.

The dataset consists of twenty in-depth semi-structured interviews with non-Chinese academic staff working on a Sino-Foreign Joint Venture/IBC. Although the participants all worked on the same IBC, they were of different ages, sexes, and nationalities and from different disciplinary backgrounds. Four of them were female; fourteen were married, four married to Chinese spouses. All of the staff were middle aged or older $(40+)$. In terms of nationality, fourteen were British, two Australian, two American, one German and one Polish. The proportions of different groups in the sample were similar to the proportions of the same groups on the campus as a whole. Individuals were selected according to their job roles to represent a range of university faculties and departments, with a preference being given to participants with leadership responsibilities since their work was particularly likely to involve the creation/re-creation of the 'home' university at departmental level.

\section{Motivations and Expectations}

Participants were asked what made them decide to apply to work on a branch campus in China. For more than half of the participants, there was a keen sense of embarking on an adventure; respondents spoke of "exploration" and visiting "a faraway land", "like the Wild West". This sense of adventure related to the geographic distance but also, importantly, to the notion of challenge:

I was recruited to set up a new programme, and to run certain things, and I've done that; and I was thinking, now what, do I do this for five, ten years more? Or do I look for some new challenge, something new, interesting... 
For eight of the participants, the challenge related to never having been to China before ("I didn't know anything about China at all”); others had made brief visits and four had worked and lived in China previously. For most interviewees, the challenge involved moving their families with them to settle; the adventure was a shared one for these interviewees.

Another aspect of the adventure and the challenge related to the newness of the project. This was particularly stressed by younger participants. They were driven by a professional curiosity and attracted to being part of a novel project, "creating a new campus", which several saw as an international experiment. The newness brought with it a sense of freedom: "we could simply develop ideas"; "there's room for lots of invention". So the potential of a new academic establishment and the spirit of engaging in an international experiment were clearly articulated as 'pull' factors for the majority of the participants.

On the other hand, there were 'push' factors related to existing roles and circumstances. Two of the twenty participants said that they "wanted a break": one from teaching and the other from his home location and the British weather. The possibility of taking up a leadership role on the IBC allowed the first of these two participants the break from teaching that he desired. Three interviewees said that they were bored with the job they had been doing ("nothing changed after my promotion; I was still doing the same things...") or bored with where they were living. Wanting something new, interesting and exciting, "far away from my normal world" were important motivating factors in their decisions to move. For some, the idea of adventure was about not staying still; these staff, and in one case the whole family, felt that "mak[ing] a new start" in a new place involved a sense of adventure which was part of their identity ("we have moved a lot in our lives").

Generally, change was seen in a positive light. Significant life changes also fed in to the motivation to make the job change. An associate professor spoke of being "newly free" because of divorce, commenting:

in some ways it was better for me to make a new start, make a new life, do something exciting, than stay in the old house, have old memories, think about old things...

So the idea of adventure, which was important to both female and male, junior and senior academic staff, contained elements of challenge and travel but also relief from boredom. The international campus in China seemed to these staff an ideal place for a "new start".

China itself was also a powerful magnet for all the interviewees: "I just wanted to be in China"; "I came to China to study China." Some wanted to take the opportunity to get "embedded in Chinese culture". Others were attracted by the rapidity of the economic growth and social changes: "If you do social sciences, and especially if you do political science and sociology, you're interested in how society is developed, and changed, and you have here a case, a society is changing very quickly..."

Some participants were attracted to the international environment in Chinese cities; others were attracted to the direct access to Chinese food, Chinese art and the opportunity to learn 
Chinese language, both for themselves and for their children. Others saw living in China as an investment in their children's future:

... from my children's point of view, China is developing very quickly and I'd really like, I really hope that three years for them will be enough to learn Chinese, at a level that they'll be able to continue later on when we go back to England - because if they grow up, and they can communicate in Chinese very well, that also will give them a great opportunity for jobs, excellent jobs in the future.

... he has lived in China since he was four. He speaks Mandarin, and for him now, living in China is fantastic. I mean I like it too, but for him it's home... it's a real gift I think to give him.

For more than half of the interviewees, however, the decision to move was not an easy one. Twelve participants spoke about the difficulties they experienced making this major decision. They spoke of "apprehension" and "hesitation" and a degree of baffled surprise amongst family and friends.

... so when I spoke to my family and friends back in the UK about this, they couldn't understand it. They were looking at me as if I was going to work on the moon or something; they just couldn't understand that I was going to China to work.

One was warned by family members about corruption, dirt and misogyny. This contrasted with four men in the sample who were married to Chinese spouses; for them, "my wife is Chinese" was part of their answer to the question of what brought them to China. Three other male participants were married to spouses who were not from their own cultures. These were families "used to living overseas", sometimes with family responsibilities in other countries closer to China than to Europe.

Nearly one third of the respondents mentioned financial reasons for taking up a post at the IBC; these were mainly younger academics. Generally, respondents recognised that jobs on the IBC were "quite lucrative" and considered their salaries good. The differential between academic salaries paid in Chinese universities and IBCs was, therefore, another motivating factor for academics to work in China, but so too was the fact of working for a Western institution:

... (I came) basically for economic reasons... because working for a Chinese university would not, they don't pay as well as the foreign universities and that would have meant that I was burning my bridges a little bit. It would have been difficult to go back...

All of the twenty participants mentioned the career aspect of their considerations on taking up the new job. Here, respondents fell into two broad groups, which corresponded to their age and career stages: one of these emphasised promotion and the other contribution.

Promotion was a salient factor in the motivation of younger academics. Three participants (all single) shared similar thoughts. One said: "I was a research associate then (six years ago) and 
I wanted to become a lecturer... so I wanted to move on and I wanted to move up." Another staff member was looking for more departmental responsibility. Both of these individuals were given more responsibilities after a year in post on the IBC. Two participants had been lecturers in British universities and were offered associate professor status for the new jobs. Both younger and more established academics tended to see career opportunities and the excitement of building something in their new job roles on the IBC.

... I didn't have any opportunity to do something, a little bit higher level. So when the opportunity for secondment here, as head of a newly established department... I was very happy to apply; and then even more happy that someone accepted me and I could come here.

The older academics talked more about their "contribution". They wanted to help "promote the university" and "share experiences". They felt that they had "sufficient seniority", knew "how the home campus thinks" and so could be important in shaping the new campus. An emeritus professor summed it up particularly well:

I was thinking much more of what I could contribute rather than what I could get out of the experience. I mean I was at the age, really, where the experience could make a lot of difference... I was more concerned, what was the contribution I could make to the (faculty). It had the opportunity to be fairly considerable... I don't mean that in the way it sounds, pompous... but it was quite clear that at the stage of development that we were at here, it needed somebody with a lot of experience of the (home university) systems...

Participants' motivations to come to China and work on the IBC therefore encompassed a variety of elements, a combination of push and pull factors that prompted each of them to the "big decision". Excitement, escape, personal and professional ambition and a certain sense of exoticism and novelty about the new situation were the main features of motivation. In terms of expectation, most of the interviewees believed that they would explore China and learn Mandarin. "Cultural immersion" in Chinese life and experiencing a multi-cultural environment were mentioned by around one third of the interviewees. There was a general and shared sense that the move would broaden experience, test their "ability to navigate" and enrich their lives:

I thought by living over here l'd get a much better insight than just by visiting... I mean I do enjoy travelling; and you learn from the experience all the time. I was hoping to get a much better insight into how Chinese people think, a much better insight into, perhaps, some of the institutions here in China and how they operate...

Those who had children also expected to improve their children's life chances. At work, expectations varied from person to person according to their individual professional plan and career status. Several interviewees expected to have more time to write better books and to improve their research. Most were expecting committed students and rewarding teaching, based on the shard view that "Chinese people are very hard-working". Younger participants shared some common expectations of getting more opportunities and experience both in 
research and in building contacts. Older interviewees expected to hold more strategic positions, gain senior managerial experiences, and develop and improve provision on the campus:

... so I thought I could put more focus on some innovations and quality... one of the things that I really enjoyed is that I've come in the phase that I have the basic things taken care of, so my job is to make things better...

Several interviewees were not entirely sure what to expect: "I didn't quite know what I was getting in to... I just had to listen and observe what's been happening, because I really wasn't sure exactly what this job would involve."

\section{The Experience of Working on the International Branch Campus}

Most participants found that aspects of the lived experience of working on an IBC surprised them. First impressions were often upsetting or even shocking. One respondent reported feeling that she had made a "terrible mistake":

Oh gosh, I'm just going to live in this field, 40 minutes outside the city with expatriates...

Another spoke of lying in bed the morning after arrival, so anxious about the move he had made that he felt unable to get up.

For the majority of the interviewees, the campus itself was the initial focus of their attention. The campus was not only their place of work, but, since staff accommodation was available on site, it also offered a temporary or, potentially, semi-permanent home in China. The decision about where exactly to live was important for all interviewees. More than half of the respondents decided to stay on campus permanently. They cited a number of reasons for this decision, related to the ease and manageability of life, safety and, above all, community. Although the desire to live in an English language campus community had not featured in their initial motivations of any of the interviewees, the pleasures of expatriate life were very rewarding to some staff:

It's the biggest positive surprise actually. It's a great community and I have made fantastic friends.

This community is amazing: we're all far away from home. I make friends of people I would never ever meet in a thousand years, people from Mongolia, from Russia, from Australia, all of the world... perhaps on the UK campus, I would not meet so many international staff - that's the best thing.

For staff with children, both the safety and the community aspects of campus life were important: "Living on campus is a real big plus, safe for the children." Others liked the fact that it took ten minutes to get from their bed to their office; also that they had the chance to ask questions and sort out the business of everyday life in a supportive English medium environment with people who had faced the same challenges. 
However, the ease, safety and manageability of living on campus were not to everyone's taste. To a greater or lesser extent, all of the participants in the study seemed to share a sense that those who chose off-campus accommodation were more adventurous and more engaged in experiencing an authentic Chinese way of life. The campus was regularly compared to a "bubble" or a "goldfish bowl":

everybody knows everybody's business; everybody knows who is doing what, it's quite gossipy...

The remaining respondents chose to live in private rented accommodation off campus. Most of these staff lived within cycling or walking distance of the campus, often close to the main supermarket that all respondents used. These interviewees tended to believe that the campus, where most of the students and many of the administrative staff lived, was not the 'real' China; it was seen as "claustrophobic", a "closed bizarre world", though ironically, life on campus was more multi-cultural in terms of the mix of nationalities than the largely monocultural Chinese quarters of the city in which staff lived.

Living off campus, managing the challenge of having Chinese landlords and neighbours with whom communication was difficult, seemed to meet some of the desire for adventure that had originally motivated many of the participants. However, every few of the respondents, whether they lived on or off campus, felt properly 'immersed' in Chinese life and culture, and those who lived off campus often felt isolated rather than welcomed (“... even when you go to the supermarket, some people will pick up your shopping in the trolley to look without asking you first..."). Meetings with neighbours were cordial but, on the whole, cursory ("very basic conversation").

The aspiration and expectation, shared by most of the interviewees, that they would learn Mandarin was definitely not realised. One of the twenty respondents spoke warmly about his personal achievement in this respect - "I can hold an hour's conversation in Chinese with locals" - and another, married to a Chinese wife, had made good progress in speaking. Otherwise, almost without exception, the interviewees were rueful, apologetic and resigned to not improving their command of the language, despite their earlier expectations, the opportunities available for language learning and the daily obstacles and misunderstandings caused by the fact that they could not communicate effectively in Mandarin. The parents in the group tended to have refocused their linguistic ambitions onto their children, whose progress in learning Mandarin they judged to be good.

The expectation that living and working in China would encourage staff to travel and explore the country also proved to be incorrect. Once they had settled in to their new jobs, most interviewees felt they were too busy with work to travel much and the travelling they did tended to be dominated by trips to the UK or their country of origin. Again, the expectations was refocused away from the self and on to family members, with one in four interviewees expressing satisfaction that, because of their employment in China, their family and friends from home could visit them and have a taste of Chinese life. 
For almost all of the interviewees, the adventure of working in China was time limited; a return to the West or a move to the next international job usually figured on the horizon. As appreciative as the parents in the group were of the opportunities they had created for their children to acquire Mandarin, live on an international campus and attend primary school in China, they usually wanted their sons and daughters to receive their secondary education elsewhere ("Primary school is okay in China, he can learn Chinese, but then next he needs to move to secondary education in England I think."). The Chinese medical system was a matter of even greater concern, for families and for the participants themselves. Even those who had Chinese spouses lacked confidence in the medical care available to them ("it's not just the language"); two interviewees spoke of difficult experiences in local hospitals and others expressed general worries:

if we had to go to a hospital... those are the things that certainly make you go 'oh God', you know... [sigh]

Those staff who started out with strong expectations about cultural and social immersion and learning at first-hand about Chinese society tended to modify and moderate their expectations as they settled in and, usually, began to give up on their earlier ambitions to gain a degree of fluency in the Chinese language. Most of the interviewees felt that their workloads (administrative and teaching) were so heavy that their time for other activities was seriously squeezed. Only three of the twenty interviewees considered their workload on the $\mathrm{IBC}$ to be set at a reasonable level; the other seventeen thought the workload was too heavy and most considered that it compared unfavourably with what would be expected on the 'home' campus. Eight respondents spoke of working exceptionally long hours and the work "never let up". Some staff considered this "entirely unreasonable" ("horrific"); some had seen a slight improvement with time; other felt the opposite, that the workload had increased ("it started heavy and got heavier"); a couple of more senior staff said it was heavy but what they had expected. Generally though, the volume and apparent relentlessness of the teaching and administrative work required of them on the IBC took the interviewees by surprise.

The participants had more mixed feelings about the research element of their roles. Half of the interviewees thought that their research benefited from their relocation to China, either because their work focused on China, or because they saw some advantage in terms of collaborative research opportunities. Six participants, two of whom were on secondment, considered that their research was well aligned with work going on in the bigger research clusters that existed on the home campus, so they felt they were bringing an international dimension to existing cross-campus departmental agendas. Other interviewees felt much more isolated; "I'm a research orphan." These respondents worried about the limitations of the branch campus, their research being misplaced and the dangers of becoming "detached". This led to anxieties about whether they were being fairly treated by the home department, for instance by being included in new research projects and bids. This concern was exacerbated by the difficulties of gaining research funding in the Chinese context: 
The European funders are reluctant to fund the equipment here because this is in China; but Chinese funders are - well, it's difficult to get funding for a British university...

These difficulties were further exacerbated by language problems, limited access to translation and interpreting support for research activities and the difficulties some experienced as 'foreigners' in gaining access to data held by Chinese institutions.

For almost all the interviewees, then, the experience of academic work on the IBC was intense and sometimes frustrating. Comparisons were made with conditions on the home campus, where things were considered to be easier. Although cross-campus collaboration was good in some instances, some interviewees felt sidelined or overlooked or marginalised by their departmental colleagues on the home campus. Those who had come to China looking for a break, or with an expansive sense that the balance between work and leisure time would allow plenty of opportunities for travel, cultural activities and language learning, generally found that their expectations were not realised.

Nevertheless, the move to the IBC did help many of the interviewees advance their careers in very tangible ways. Respondents were satisfied with the standard of living their salaries allowed them to enjoy, and half of the sample group was promoted either whilst they were working on the IBC or immediately in advance, as a consequence of taking up the post in China. Those nearing the end of their careers, who placed a particular emphasis on the contribution they might make to the successful development of the campus, generally found their work rewarding and felt that their contribution was valued.

\section{Discussion}

The academic staff interviewed for this study were energetic, eager to experience change, ready to experiment and innovate. As individuals, and sometimes as family units, a lot was at stake in deciding to make the move to work abroad. In preparing for the move, most of the respondents focused on the cultural changes they expected to experience; they were internationally-minded, curious about the country they were going to live in and, once they had made the decision to move, most of them focused on the excitement of making arrangements, telling (often surprising) friends and family and setting off on what seemed like an adventure, or to a few, perhaps even a long working holiday. Very few of the interviewees focused much at this time on the nature of the work they would be doing when they arrived: how it would differ from their previous academic roles, what it would mean (for almost all of them) to work on a relatively small campus which was just one component of a much larger institution.

None of the respondents had investigated in any depth the structural aspects of how the university was set up in the international context (in the specific example of this study, the question of what it would mean to work in a joint venture institution in China). For a significant number of the interviewees, this meant that they expected the IBC to operate as a microcosm of the home campus transplanted to a new context although, in fact, the terms of the joint venture agreement for the IBC they worked on meant that a Chinese partner had 
responsibility for the campus infrastructure, which included the management of the buildings and of the administrative, technical and support staff. This meant that some of the norms of routine work life were different. They were surprised and sometimes upset when this proved to be the case; (usually negative) comparisons with the home campus became the frame of reference rather than an attempt to understand the IBC as an entity in its own right. This framing was reinforced by university level discourse in marketing, policy and management texts which minimised the differences between sites and emphasised the idea of one unified institution that operated across international boundaries. So the particular contribution of the IBC to the university as a whole was neither specified to the staff by senior management nor publicly debated within the staff community.

The strategic paradox identified by Shams and Huisman (2011), between global integration and local responsiveness, figured obliquely but recurrently throughout the interviews. The offer of a British education in China was fundamental to the joint venture and to the branding of the university. However, the question of what constituted the 'Britishness' of the education being offered by the IBC was not a matter of professional debate amongst staff. British education was promoted at a general level as involving English as a medium of instruction, opportunities for student mobility, certain expectations about criticality and types of classroom engagement, and degrees that were sanctioned by the British system. But as the staffing on the IBC became more international and the proportions of academics from mainland Europe, the US and Australia increased, knowledge about the ethos and mores of the 'home' institution - and the British education that it offered - became more tenuous. Ironically, therefore, although as a private institution in China the IBC relied in part upon its distinctive Britishness to market its courses and attract students, there appeared to be no ongoing work amongst the staff to define, maintain and develop the ethos and values that supported this distinctiveness in the Chinese context. The corporate branding of the university, led by the home campus, created a homogenising discourse of one international university which minimised difference and embraced, but did not explore, diversity.

At their induction, staff had not been well briefed about the nature of and reasons for the differences between the campuses and the specific agreements and political requirements that dictated some of the arrangements on the IBC. Whilst this information was probably readily available to staff, it was not knowledge that they sought out for themselves in the first stage of anticipating the move and relocating. There was also a marked lack of ongoing professional development to help staff better understand and manage their new work lives once they had arrived in China. Staff development related to disciplinary and subject identities featured strongly in the interviewees' professional concerns, but it was clear that there had been no systematic attempt to help staff work together to understand the social and political differences, constraints and advantages of working as academics on the IBC. Campus identity, which was strong in social and community terms, was relatively weak at the professional level.

Because staff had not, on the whole, thought a great deal about the nature of the work in advance of arriving at the campus, those with a significant teaching role had not been prepared for the workload involved in creating new materials and adapting existing resources 
for the new context. Whilst they were generally highly complimentary about the students they taught, the classes were different to the ones they were used to teaching. One of the realities of the 'experiment' many had looked forward to was that energy needed to be put into curriculum renewal. For researchers who were not already well established internationally, there were difficulties in accessing funding, data sets and in understanding the rules and regulations that applied to research in the Chinese context. Staff could have been prepared better for these differences in their work before arrival but also through ongoing professional development on the IBC.

Students on the IBC were expected to speak English in class and they were given significant amounts of support and encouragement to improve their competence. Although classes were available on the campus, there was no strong institutional push for staff to learn Mandarin; generally the culture was of cheerful failure to make any progress. So learning Mandarin was seen as an optional extra, not part of the commitment to the job and to understanding to context. Arguably, this restricted staff in their personal lives and in career terms; arguably, lack of engagement with the language contributed to the sense of foreignness and otherness, which was a strong theme in the interviewees' accounts. The sociality of the campus might have been better used to encourage collaborative learning about Chinese language and culture.

\section{Conclusions and Recommendations}

This study elaborates on the expatriate academic identities encapsulated in Richardson and McKenna's (2000) metaphors; it supports the argument made by Tsang (2001), Dunn \& Wallace (2006), Gribble \& Ziguras (2003) and Hoare (2013) about the importance of predeparture induction and social support. The study is limited in sample size and conducted on a single site. Nevertheless, we suggest that there are two main areas in which these findings might be helpful in supporting the development of other international ventures.

The first relates to staff induction. In the pre-departure stages, unsurprisingly, staff were preoccupied with the personal investment they were making in moving to China. All of the staff interviewed for this study had weighed the possible risks against the possible benefits to their careers, their personal and family lives; they were excited, often idealistic and sometimes unrealistic. However, they were not well prepared by the university for the differences and difficulties they would experience in their academic work on the IBC. The political context of HEls in China and implications of the joint venture agreement were glossed over, rather than explored with staff; despite their professional engagement in critique, analysis and problem-solving, the challenges and constraints of the IBC were not shared with them. This was a wasted opportunity both in terms of preparing the staff and of engaging them from the outset in working to improve the IBC.

Post arrival, the domestic and social needs of expatriate staff tended to take immediate priority; in this study these needs were generally well catered for. However, there was no systematic campus-level professional development programme. Professional development 
needs were managed individually and, sometimes, in a relatively ad hoc manner, a situation which seems likely to be exacerbated as staffing models become more complex (Salt \& Wood, 2014). Our second recommendation therefore relates to the need for targeted, ongoing and collective professional development, to bring staff together to analyse and learn more about their particular professional context, explore and understand the differences they are experiencing, build intercultural and linguistic knowledge, and develop their understanding of the university's corporate aims for the IBC. At the institutional level, inclusive and sustained professional development of this kind opens up opportunities to refine and contextualise strategic priorities and build corporate identity. At the individual level, it seems likely to help staff gain more of the insights into Chinese life and culture that many are seeking when they apply for jobs on IBCs.

\section{References}

AP. (2011). Future of State Universities. Available at http://www.futureofstateuniversities.com

Altbach, P.G. (2009) One-third of the globe. The future of higher education in China and India. Prospects, 39(1), 11-31

Austin, A.; Chapman, D.; Farah, S.; Wilson, E.; Ridge, N. (2014) Expatriate academic staff in the United Arab Emirates: the nature of their work experiences in higher education institutions. Higher Education 68 (4), 541-557

Barrows, L. C. (Ed)(2000). Internationalization of Higher Education: an Institutional Perspective CEPES Papers on Higher Education: UNESCO.

Bodycott, P. \& Walker, A. (2000) Teaching abroad: Lessons learned about inter-cultural understanding for teachers in higher education. Teaching in Higher Education, 5, 79-94

Cross-Border Education Research Team (2015, August). C-BERT Branch Campus Listing. [Data originally collected by Kevin Kinser and Jason E. Lane]. Available at: http://globalhighered.org/branchcampuses.php Albany, NY: Author.

Chapman, D., Austin, A., Farah, S., Wilson, E., \& Ridge, N. (2014) Academic Staff in the UAE: Unsettled Journey Higher Education Policy, 27, 131-51

Chiang, L.C. (2012). Trading on the West's strength: the dilemmas of transnational higher education in East Asia. Higher Education Policy, 25(2), 171-189

China. (2010). Outline of China's national plan for medium and long-term education reform and development 2010-2020. Available at: asemlllhub.org/fileadmin/www.asem.au.dk/LLL_Policies/China

De Wit, B., \& Meyer, R. (2004). Strategy: Process, content, context; An international perspective. London: Thomson Learning.

Dessoff, A. (2011). Cultivating branch campuses. International Educator, 11, 19-27.

Dobos, K. (2011) "Serving Two Masters"- Academics' Perspectives on Working at an Offshore Campus in Malaysia. Educational Review, 63, 19-35

Dunn, L. \& Wallace, M. (2006) Australian Academics and Transnational Teaching: an exploratory study of their preparedness and experiences Higher Education Research and Development, 25, (4)357369

Dunn, L. \& Wallace, M. (Eds) (2008) Teaching in Transnational Higher Education: enhancing learning for offshore international students Abingdon and New York: Routledge

Ferguson, M. R. (2011). Finding a Home Abroad With "Eveline": Using Narrative Inquiry to Establish a Sense of Place for a Western Teacher in a Foreign and Multicultural Context. Journal of Studies 
in International Education, 15(1), 25-40.

Fielden, J. (2010) Leadership and Management of International Partnerships, Research and Development, Vol. 2 Leadership Foundation for Higher Education and L.H. Martin Institute for Leadership and Management.

Fielden, J., \& Gillard, E. (2011). A guide to offshore staffing strategies for UK universities (including Case Studies) (Research Series 7). London : UK Higher education International and Europe Unit, Leadership Foundation for Higher Education.

Froese, F. J. (2011). Motivation and adjustment of self-initiated expatriates: the case of expatriate academics in South Korea. The International Journal of Human Resource Management, 23(6), 1095-1112.

Gannon, M. J. (2008). Paradoxes of Culture and Globalization. Los Angeles; London; New Delhi; Singapore: Sage.

Garson, B. (2005). Teaching Abroad: A Cross-Cultural Journey. Journal of Education for Business, 80 (6), 322-326.

Gribble, K \& Ziguras, C. (2003) Learning to Teach Offshore: pre-departure training for lecturers in transnational programs. Higher Education Research and Development, 22 (2), 205-216

Helms, R.M. (2008) Transnational Education in China: key challenges, critical issues and strategies for success. The Observatory on Borderless Higher Education.

Hoare, L. (2013) Swimming in the Deep End: transnational teaching as culture learning? Higher Education Research and Development, 32, 561-74

Hughes, R. (2011). Strategies for managing and leading an academic staff in multiple countries. New Directions for Higher Education, 155, 19-28

Keevers, L., Lefoe, G., Leask, B., Sultan, F. K. P. D., Ganesharatnam, S., Loh, V., \& Lim, J. S. Y. (2014) 'I like the people I work with. Maybe I'll get to meet them in person one day': teaching and learning practice development with transnational teaching teams. Journal of Education for Teaching, 40(3), 232-250

Morgan, W.J. \& Wu, B. (2011) Higher Education Reform in China: beyond the expansion Abingdon and New York: Routledge

Olcott Jr, D. (2009) Global connections to global partnerships: navigating the changing landscape of internationalism and cross-border higher education. The Journal of Continuing Higher Education 57(1), 1-9

Richardson, J., \& McKenna, S. (2000). Metaphorical "types" and human resource management: selfselecting expatriates. Industrial and Commercial Training 32(6), 209-219.

Sadler, D. (2015) The challenges facing Chinese higher education - and why they matter. The Observatory on Borderless Higher Education.

Salt, J., \& Wood, P. (2014). Staffing UK University Campuses Overseas: Lessons from MNE Practice. Journal of Studies in International Education 18(1), 84-97.

Selmer, J., \& Lauring, J. (2009). Cultural similarity and adjustment of expatriate academics. International Journal of Intercultural Relations, 33 (5), 429-436.

Shams, F., \& Huisman, J. (2012). Managing Offshore Branch Campuses: An Analytical Framework for Institutional Strategies. Journal of Studies in International Education 16 (2), 106-127

Shams, F., \& Huisman, J. (2014). The role of institutional dual embeddedness in the strategic local adaptation of international branch campuses: evidence from Malaysia and Singapore. Studies in Higher Education, doi:10.1080/03075079.2014.966669.

Shaw, C. (2013). Staff experience: how can universities improve HE working life? The Guardian Professional Networks Available at http://www.guardian.co.uk/higher-educationnetwork/2013/feb/06/hr-staff-experience-universities-support 
Smith, L. (2009) Sinking in the Sand Academic work in an offshore campus of an Australian university Higher Education Research and Development, 28, 467-79.

Stanfield, D. A., \& Qi, W. (2012). Full-Scale Branch Campuses in China. International Higher Education, 69 (Fall), 13-15.

Tsang, E. W. K. (2001). Adjustment of mainland Chinese academics and students Singapore. International Journal of Intercultural Relations, 25( 4), 347-372.

University World News (2015) While branch campuses proliferate, many fail. Available at: http://www.universityworldnews.com/article.php?story=20150219113033746

World Bank (2011) Putting Higher Education to Work: skills and research for growth in East Asia. Washington D.C.: World Bank East Asia and Pacific Regional Report

Ziguras, C. (2008). The cultural politics of transnational education: ideological and pedagogical issues for teaching staff. In Dunn and Wallace, (Eds), Teaching in Transnational Higher Education: enhancing learning for offshore international students Abingdon and New York: Routledge 